\title{
Analytical Method for Forming Limit Diagram Prediction with Application to a Magnesium ZEK100-0 Alloy
}

\author{
Junying Min, Louis G. Hector Jr., Jianping Lin, and Jon T. Carter
}

\author{
(Submitted February 12, 2013; published online July 17, 2013)
}

\begin{abstract}
A significant barrier to broader implementation of magnesium alloys is their poor room temperature formability, a consequence of the anisotropic response of the $\mathrm{Mg}$ hexagonal closed-packed (hcp) crystal structure. Additions of rare earth (RE) elements, such as in the ZEK100 alloys, weaken the texture and improve formability. Room temperature forming limit analyses of RE-containing Mg alloys, particularly Mg ZEK100, have not been explored to any significant extent in the literature. In this paper, strain-based forming limit diagrams (FLDs) are derived for an Mg ZEK100-O alloy (Zn1.34Zr0.23Nd0.182, wt.\%) using an analytical method that combines the vertex theory of Storen and Rice (J Mech Phys Solids, 23:421-441, 1979), the anisotropic yield criterion of Barlat and Lian (Int J Plast, 5:51-66, 1989), and a hardening law. The method does not rely on assumptions about pre-existing defects, is broadly applicable to sheet alloys exhibiting in-plane anisotropy requiring a higher-order yield criterion, and requires only minimal experimental inputs. Results from the analytical method are compared with experimentally derived FLDs based upon the well-known Nakajima test and tensile deformation, and with predictions from an existing analytical method for FLDs. Close agreement between the experimentally derived FLDs and the present theoretical method was obtained. Sheet materials where the theoretical method does not apply are also discussed.
\end{abstract}

Keywords formability, forming limit diagram (FLD), in-plane anisotropy, yield point elongation, ZEK100 magnesium alloy

\section{Introduction}

The compelling need for energy efficiency combined with mounting concerns for the environmental impact of greenhouse gas emissions is generating strong motivation for the increased use of lightweight engineering materials that will lead to weight reduction in transportation industries. The automotive industry in particular has been focused on development of magnesium $(\mathrm{Mg})$ alloys to meet stringent vehicle mass reduction targets required by forthcoming CAFÉ requirements (Ref 1) without compromising occupant safety. As the lightest of all structural metals, Mg alloys hold great promise as replacement materials for heavier steel and aluminum. With high strength-to-weight ratios and low densities $(\sim 35 \%$ lighter than aluminum and $\sim 78 \%$ lighter than steel), $\mathrm{Mg}$ alloys are potentially suitable for a large variety of component. However, broader implementation of $\mathrm{Mg}$ sheet alloys has been hampered by poor room temperature (RT) formability. The von Mises criterion (Ref 2) for strain compatibility requires the operation of at least five independent systems (slip and twinning), and these are not

Junying Min and Jianping Lin, School of Mechanical Engineering, Tongji University, Shanghai 201804, China; and Louis G. Hector Jr., and Jon T. Carter, General Motors R\&D Center, General Motors, 30500 Mound Road, Warren, MI 48090. Contact e-mails: junying.min@ gmail.com, louis.hector@gm.com, jplin58@tongji.edu.cn, and jon.t.carter@ gm.com. available at RT due to the very high stresses needed to operate non-basal slip systems: fracture precedes plastic deformation resulting in low polycrystalline ductility. Magnesium sheet forming processes are typically conducted at warm temperatures (e.g., stamping, $\sim 200-300{ }^{\circ} \mathrm{C}$ ) or hot temperatures (e.g., gas pressure forming, $>300{ }^{\circ} \mathrm{C}$ ). Examples are Ambrogio et al. (Ref 3) who investigated the hot incremental forming of $\mathrm{Mg}$ AZ31 alloy sheet, and Carter et al. (Ref 4) who formed Mg AZ31 at $450{ }^{\circ} \mathrm{C}$ by hot gas pressure forming. The addition of heat can add manufacturing cost and process intensity rendering RT forming the desirable alternative.

Substantial effort has therefore been focused on improving the RT ductility of $\mathrm{Mg}$ sheet alloys with both experimental and theoretical approaches. For example, Ha et al. (Ref 5) suggested a method for increasing the ductility of $\mathrm{Mg}$ alloy sheets by using a laser scanning treatment combined with a defocusing technique. Yasi et al. (Ref 6) developed a model of thermally activated cross-slip in $\mathrm{Mg}$ based upon first principles density functional theory and showed that solutes such as $\mathrm{K}, \mathrm{Na}$, and $\mathrm{Sc}$ can lower the prismatic stacking fault energy providing a modest improvement in formability at lower temperatures. Another approach to improving RT ductility of $\mathrm{Mg}$ alloys is through the addition of rare earth (RE) elements, such as La, $\mathrm{Ce}, \mathrm{Nd}$, and Pr, often in the form of misch metal (Ref 7-10). Improved RT ductility results from softening of the recrystallization texture along with increased activity of otherwise inactive deformation mechanisms: $\{10 \overline{1} 1\}\langle 10 \overline{1} 2\rangle$ compression twins, $\{10 \overline{1} 1\}\{10 \overline{1} 2\}$ double twinning, and pyramidal $\langle c+a\rangle$ dislocation slip (Ref 11-14). Zhang et al. (Ref 15) showed that addition of Er softens the $\mathrm{Mg}$ texture and increases RT ductility. Al-Samman and Li (Ref 13) demonstrated that additions of Gd, $\mathrm{Nd}, \mathrm{Ce}, \mathrm{La}$ as misch metal elements weaken the $\mathrm{Mg}$ texture and anisotropy relative to conventional $\mathrm{Mg}$ sheet alloys (e.g., 
AZ31), especially after recrystallization annealing. Magnesium ZEK100 alloys, which have attracted particular attention, typically consist of $\mathrm{Zn}$ (for strength), RE (for reduced texture), and $\mathrm{Zr}$ (for grain refinement) (Ref 16). Potential applications of $\mathrm{Mg}$ ZEK100 alloys in the automotive industry are doors, decklids, liftgate inner panels, seat backs, and other reinforcements. Current drawbacks to the use of Mg ZEK100 are primarily related to material and manufacturing costs and the likelihood that a coating or paint would be needed to heal scratches if the Mg ZEK100 alloy were used as an autobody outer panel (for example).

A critical step in sheet component manufacturing is the development of forming limit diagrams (FLDs) which consist of forming limit curves (FLCs). First introduced by Keeler (Ref 17) and Goodwin (Ref 18), FLCs are empirical relationships between critical (or limiting) in-plane strains that describe the limit of sheet formability as now defined by ASTM E2218 (Ref 19). The FLCs divide combinations of major and minor strains that are "safe", i.e., for which failure is not expected from a given strain combination in an FLD. The major strain is along the vertical ( $y$-axis) and the minor strain is along the horizontal ( $x$-axis) of the FLD (Ref 20). Localized necking is usually the failure mechanism of interest since necked regions are potential fracture sites in stamped automotive components (note that key distinctions between "diffuse" and "localized" necking are detailed in Hosford and Cadell (Ref 21)). The left side of the FLD corresponds to strain combinations appropriate for drawing and uniaxial tension, and the right side corresponds to strain combinations for biaxial stretching. The plane strain limit corresponds to the point where an FLC intersects the major strain axis. Data required to generate an FLD are produced in a set of ancillary experiments (i.e., in addition to those required for constitutive models of flow behavior) in which sheet specimens with different geometries are deformed with a punch. Strain fields on the surface of the deformed specimens are measured either with etched grids consisting of an array of circular elements or with digital image correlation, a whole field optical strain mapping technique (Ref 22). A useful review of strain-based FLDs may be found in Marciniak et al. (Ref 23). There is currently an important effort underway to develop stress-based FLDs (not considered in this paper). As discussed by Stoughton (Ref 24), the stress-based approach has some advantages over the ubiquitous strain-based approach that may well result in its being the preferred method in the future.

Since experimentation can be costly and time consuming, there has been some effort aimed at predicting strain-based FLDs using various theoretical methodologies. Theoretical prediction of FLDs for thin sheet materials of relevance to transportation industries has been based upon one of three existing theories. The first is due to Hill (Ref 25), and it assumes that a localized deformation band or neck forms along the zero-extension direction and an angle exists between the normal direction of the neck in the sheet plane and the major strain direction: this is the so-called "zero-extension hypothesis". However, Hill's zero-extension hypothesis is only applicable to the left-hand side (LHS) of the FLD, since no zero-extension direction exists in a stretched sheet with positive minor strain, and of course prediction of localized necking is not possible. The second theory is based on the groove (or initial thickness inhomogeneity) hypothesis by Marciniak and Kuczynski (Ref 26), also known as the "M-K theory." This postulates that localized necking develops from a geometric inhomogeneity or groove in the initial sheet thickness from which localized necking develops. The obvious physical significance of the M-K theory and its simple mathematical form have contributed to its widespread application for more than four decades. For example, Cao et al. (Ref 27) used the M$\mathrm{K}$ theory to compute the FLDs of Al2008-T4 and Al6111-T4 alloys while McCarron et al. (Ref 28) investigated failure of NAPAC F-50 and AK-Rephos sheet steels. Unfortunately, models based upon the $\mathrm{M}-\mathrm{K}$ theory are over-sensitive to the assumed initial thickness inhomogeneity as discussed by Ghazanfari and Assempour (Ref 29) and Min et al. (Ref 30). In addition, there have been several published studies that question the extent to which an initial geometric inhomogeneity is the direct cause of localized necking. For example, Zhang and Wang (Ref 31) showed that localized geometric softening at a certain state of deformation is in fact the cause of localized necking in 2036-T4 aluminum rather than an initial geometric inhomogeneity. The third theory is the vertex theory by Storen and Rice (Ref 32), also known as the "S-R theory". Here, it is assumed that localized necking corresponds to a corner or vertex that develops on the yield surface at the loading point, and a localized necking criterion is developed for the deformation on both sides of an FLD based on the $J_{2}$ deformation theory of plasticity. The vertex theory was recently modified by Zhu et al. (Ref 33). Based on their modified theory, Chow and Jie (Ref 34) developed an analytical model coupled with material damage for the FLD of Al alloy AA6022 considering Hill's 48 yield criterion, and Min et al. (Ref 30) derived an analytical model with the Logan-Hosford yield criterion and inplane isotropy (Ref 35) for the FLD of $22 \mathrm{MnB} 5$ steel at $800{ }^{\circ} \mathrm{C}$. Jie et al. (Ref 36 ) deduced a model based upon the von Mises yield criterion and isotropy for a rate-dependent material and validated their model with forming limit tests of a ratedependent AKDQ steel.

Theoretical prediction of the FLD of sheet alloys requires a yield criterion and a hardening model. Various non-quadratic (or higher-order) yield criteria developed over the past 30 years or so are good candidates. For example, Hosford (Ref 35) developed a higher-order yield criterion, and suggested an order of 6 and 8 for body-centered cubic (BCC) and face-centered cubic (FCC) metals, respectively. Barlat et al. (Ref 37-42) proposed high-order yield criteria known as Yld89, Yld91, Yld94, Yld97, Yld2000, and Yld2004, respectively. Recently, Cazacu et al. (Ref 43) developed an orthotropic yield criterion for hexagonal close-packed (HCP) metals. The yield criterion proposed by Hill (Ref 44), known as Hill's 1948 criterion, is still widely employed since it has a relatively simple mathematical form. However, Naka et al. (Ref 45) and Min et al. (Ref 30) showed, respectively, that higher-order yield criterion must be adopted to obtain reasonable predictions for $\mathrm{Mg}$ alloys and hot sheet steels. Bohlen et al. (Ref 12) found that $\mathrm{Mg}$ sheet alloys exhibit orthotropic plasticity or in-plane anisotropy. Nevertheless, most of the theoretical methods based on highorder anisotropic yield criterion do not consider in-plane anisotropy due to mathematical complexity. For example, the Yld97 (Ref 40) and Yld2000 (Ref 41) include 6 and 8 fitting constants, respectively. A notable exception, however, is the theoretical FLD model of Zhu et al. (Ref 46) in which Hill's 48 yield criterion (Ref 44) was employed to predict FLDs based upon Hill's zero-extension hypothesis (Ref 25) and in-plane anisotropy was also considered, They concluded that the Lankford coefficient $r_{0}$ effects the FLC significantly on the RHS of the FLD, but has only minimal effect on the LHS of the FLD; however, both $r_{45}$ and $r_{90}$ have little effect on the FLC. 
Most of the available information on forming limits for $\mathrm{Mg}$ sheet alloys has been generated at high temperatures, a consequence of their poor RT ductility. For example, Abu-Farha et al. (Ref 47) performed forming limit tests for four $\mathrm{Mg}$ AZ31B sheets at $400{ }^{\circ} \mathrm{C}$ using elliptical dies. Siegert et al. (Ref 48) investigated the formability of an Mg AZ31B sheet material over the $200-350{ }^{\circ} \mathrm{C}$ temperature range. Kim et al. (Ref 49) generated FLCs for Mg AZ31 using elevated temperature punch stretching tests. RT forming limit analyses of RE-containing $\mathrm{Mg}$ alloys have not been explored to any significant extent in the literature. In particular, there is no existing information on RT, strain-based FLDs for Mg ZEK100 sheet alloys.

In this paper, strain-based FLDs are derived for an $\mathrm{Mg}$ ZEK100-O alloy (Zn1.34Zr0.23Nd0.182, wt.\%) using an analytical method that combines the vertex theory of Storen and Rice (Ref 32), the anisotropic yield criterion of Barlat and Lian (Ref 37), and a hardening law. The model does not rely on assumptions about pre-existing defects, is broadly applicable to sheet alloys exhibiting in-plane anisotropy requiring a higherorder yield criterion, and requires only minimal experimental inputs. Uniaxial tensile tests of Mg ZEK100-O sheets were conducted to obtain the Lankford coefficients (or $r$ values) at $0^{\circ}$, $45^{\circ}$, and $90^{\circ}$ with respect to the rolling direction (RD), and the well-known Nakajima test was used to measure the FLDs for comparison with model predictions. Predictions of the analytical method are shown to be in closer accordance with experimental FLD data compared with the Zhu et al. (Ref 33) method for FLD prediction. In addition, the analytical method addresses the yield point elongation (YPE) exhibited by Mg ZEK100-O tensile specimens with a $90^{\circ}$ gage orientation. Sheet materials where the analytical method does not apply are also discussed.

\section{Analytical Method for Strain-Based Forming Limits}

\subsection{Vertex Theory}

According to the vertex theory of Storen and Rice (Ref 32), the localized necking of a sheet material corresponds to the appearance of a vertex on the yield surface. The stress and strain across the necking band in a sheet are considered to be continuous, while the stress rate is discontinuous. It is assumed that the angle between the normal direction of the necking band

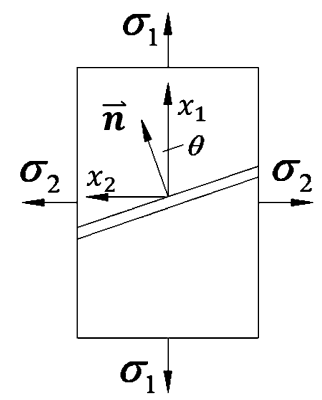

Fig. 1 Illustration of a localized necking band (parallel lines running across the figure) under Hill's zero-extension hypothesis. $\sigma_{1}$ and $\sigma_{2}$ are major and minor stresses, respectively. The unit vector $\vec{n}$ indicates the normal direction of the necking band and $\theta$ is the angle between $\vec{n}$ and the major stress direction and the direction of the major strain is $\theta$ (see Fig. 1): this corresponds to the zero-extension hypothesis proposed by Hill (Ref 44). Note that $\theta$ is 0 when considering the case of the right-hand side (RHS) of the FLD since no zero-extension direction exists in a stretched sheet with positive minor strain. Hence, the discontinuity across the necking band can be expressed as

$\Delta v_{i}=f_{i}\left(n_{k} x_{k}\right) \quad(i, k=1,2)$

where $n_{k}(k=1,2)$ is the component of the unit normal vector $\vec{n}$ of the necking band, $n_{1}=\cos \theta$, and $n_{2}=\sin \theta$.

The gradient of the deformation rate in-and-out of the necking band is

$\Delta\left(\frac{\partial v_{i}}{\partial v_{j}}\right)=\frac{\Delta\left(\partial v_{i}\right)}{\partial x_{j}}=f_{i}^{\prime}\left(n_{k} x_{k}\right) n_{j}=g_{i} n_{j}$

where $v_{i}$ is the velocity of a point on the material surface and $g_{i}=f_{i}^{\prime}\left(n_{k} x_{k}\right)(i, k=1,2)$. Using $\dot{\varepsilon}_{i j}=\partial v_{i} / \partial x_{j}$, Eq 2 can be expressed in terms of principal axes

$\Delta \dot{\varepsilon}_{1}=g_{1} n_{1}, \quad$ and $\Delta \dot{\varepsilon}_{2}=g_{2} n_{2}$

Here $\varepsilon_{1}$ and $\varepsilon_{2}$ are major and minor strains, respectively, and $\dot{\varepsilon}_{1}$ and $\dot{\varepsilon}_{2}$ are major and minor strain rates, respectively. By considering the moment equilibrium equation in the force equilibrium condition, the equilibrium equations in the modified vertex theory of Zhu et al. (Ref 33) have the following forms

$\left\{\begin{array}{l}\Delta \dot{\sigma}_{1}-\sigma_{1}\left(g_{1} n_{1}+g_{2} n_{2}\right)=0 \\ \Delta \dot{\sigma}_{2}-\sigma_{2}\left(g_{1} n_{1}+g_{2} n_{2}\right)=0\end{array}\right.$

As mentioned before, the necking band is normal to the major strain direction on the RHS of the FLD. Hence

$n_{1}=1$, and $n_{2}=0$

Thus,

$$
\begin{aligned}
\Delta \dot{\varepsilon}_{1} & =g_{1} n_{1}, \text { and } \Delta \dot{\varepsilon}_{2} \\
& =\left\{\begin{array}{cl}
g_{2} n_{2}=\rho_{\varepsilon} g_{1} n_{1} & \text { in the negative minor strain region } \\
0 & \text { in the positive minor strain region }
\end{array}\right.
\end{aligned}
$$

where $\rho_{\varepsilon}$ is the strain ratio

$\rho_{\varepsilon}=\varepsilon_{2} / \varepsilon_{1}$

The simplification of the vertex theory makes possible the consideration of high-order yield criteria that are much more complex than the Hill's quadratic yield criterion. Kim et al. (Ref 50), Zhang et al. (Ref 51), and Min et al. (Ref 30) have shown that incorporation of high-order yield criteria generally improves the FLD prediction relative to experiments for Al sheet alloys and for boron steel (for example) at elevated temperatures.

\subsection{Orthotropic High-Order Yield Criterion}

The orthotropic, higher-order yield function proposed by Barlat and Lian (Ref 37), also known as Yld89, which contains only three parameters that need to be determined: $a, c$, and $m$, is employed in this study. It has a much simpler form than either Yld91 (Ref 38) or Yld94 (Ref 40) as well as the yield criterion developed for HCP metals by Cazacu et al. (Ref 43). The 
simple form of Yld89, which allows one to analytically deduce the necking criterion for a sheet alloy, is

$f\left(\sigma_{i}\right)=\frac{a}{2}\left|K_{1}+K_{2}\right|^{m}+\frac{a}{2}\left|K_{1}-K_{2}\right|^{m}+\frac{c}{2}\left|2 K_{2}\right|^{m}=\sigma_{\text {eq }}^{m}$

where

$K_{1}=\frac{\sigma_{11}+h \sigma_{22}}{2}, \quad K_{2}=\sqrt{\left(\frac{\sigma_{11}-h \sigma_{22}}{2}\right)^{2}+p^{2} \sigma_{12}^{2}}$

$c=2-a$,

$a=2-2 \sqrt{\frac{r_{0}}{1+r_{0}} \times \frac{r_{90}}{1+r_{90}}}$,

$h=\sqrt{\frac{r_{0}}{1+r_{0}} \times \frac{1+r_{90}}{r_{90}}}$

$P(p)=\frac{2 m \sigma_{\mathrm{eq}}^{m}}{\sigma_{12}\left(\frac{\partial f}{\partial \sigma_{11}}+\frac{\partial f}{\partial \sigma_{22}}\right)}-1-r_{45}$.

Here, $\sigma_{i j}(i, j=1,2)$ are the stress components and $\sigma_{\mathrm{eq}}$ is the equivalent stress; $m$ is recommended to be 6 and 8 for BCC and FCC metals by Barlat and Lian (Ref 37) and Dixit and Dixit (Ref 52), respectively. Note that $K_{1}$ and $K_{2}$ are the plane stress tensor invariants; $a, c, h$, and $p$ are material constants that depend upon Lankford's coefficients (or $r$ values) $r_{0}, r_{45}, r_{90}$.

Let the stress axes be coincident with the principal coordinate system. Then $\sigma_{12}=0, \sigma_{11}=\sigma_{1}, \sigma_{22}=\sigma_{2}$; here, $\sigma_{1}$ and $\sigma_{2}$ are the major and minor stresses, respectively. For simplicity, let $k=\sqrt{\frac{r_{0}}{1+r_{0}} \times \frac{r_{90}}{1+r_{90}}}$. Then the Barlat-Lian orthotropic yield criterion can be rewritten as

$f\left(\sigma_{i}\right)=\left[(1-k) \sigma_{1}^{m}+(1-k) \sigma_{2}^{m}+k\left(\sigma_{1}-h \sigma_{2}\right)^{m}\right]=\sigma_{\mathrm{eq}}^{m}$

If $m=2$ (where $m$ is the order of the yield criterion), and $r_{0}=r_{90}=r$ (without consideration of in-plane anisotropy), then $h=1, k=r /(1+r)$, and Eq 10 becomes

$\sigma_{\mathrm{eq}}^{2}=\sigma_{1}^{2}-\frac{2 r}{1+r} \sigma_{1} \sigma_{2}+\sigma_{2}^{2}$

which is Hill's quadratic yield criterion ( $\sigma_{\mathrm{eq}}$ is equivalent stress). Normality of plastic strain increments requires

$d \dot{\varepsilon}_{i}=d \dot{\lambda} \frac{\partial f}{\partial \sigma_{i}}, \quad(i=1,2)$

where $\lambda$ is a scalar quantity. The major and minor strains, $\varepsilon_{1}$ and $\varepsilon_{2}$, respectively, can be obtained by integrating Eq 12 after substituting Eq 10 for $f$

$\left\{\begin{array}{l}\varepsilon_{1}=\varepsilon_{\mathrm{eq}} \frac{(1-k) \sigma_{1}^{m-1}+k\left(\sigma_{1}-h \sigma_{2}\right)^{m-1}}{\sigma_{\mathrm{eq}}^{m-1}} \\ \varepsilon_{2}=\varepsilon_{\mathrm{eq}} \frac{(1-k) \sigma_{2}^{m-1}-k h\left(\sigma_{1}-h \sigma_{2}\right)^{m-1}}{\sigma_{\mathrm{eq}}^{m-1}}\end{array}\right.$

where $\varepsilon_{\text {eq }}$ is the equivalent strain. The strain ratio $\rho_{\varepsilon}$ can now be expressed as $\rho_{\varepsilon}=\frac{\varepsilon_{2}}{\varepsilon_{1}}=\frac{(1-k) \rho_{\sigma}^{m-1}-k h\left(1-h \rho_{\sigma}\right)^{m-1}}{(1-k)+k\left(1-h \rho_{\sigma}\right)^{m-1}}$

$\rho_{\sigma}=\frac{\sigma_{2}}{\sigma_{1}}$

Note that $\varepsilon_{1}$ and $\varepsilon_{2}$, which follow from the normality rule (Eq 12) and the Barlat-Lian orthotropic yield criterion can now be used to develop the analytical model for the FLD.

\subsection{Localized-Necking Criterion for Sheet Alloys}

By differentiating Eq 13 with respect to time, the following two evolution equations can be derived

$$
\left\{\begin{array}{c}
\dot{\varepsilon}_{1}=\left[\dot{\varepsilon}_{\mathrm{eq}} \sigma_{\mathrm{eq}}^{1-m}-\varepsilon_{\mathrm{eq}} \sigma_{\mathrm{eq}}^{-m} \dot{\sigma}_{\mathrm{eq}}(m-1)\right] \\
\times\left[(1-k) \sigma_{1}^{m-1}+k\left(\sigma_{1}-h \sigma_{2}\right)^{m-1}\right] \\
+\varepsilon_{\mathrm{eq}} \sigma_{\mathrm{eq}}^{1-m}\left[(1-k)(m-1) \sigma_{1}^{m-2} \dot{\sigma}_{1}\right. \\
\left.+k(m-1)\left(\sigma_{1}-h \sigma_{2}\right)^{m-2}\left(\dot{\sigma}_{1}-h \dot{\sigma}_{2}\right)^{m-1}\right] \\
\dot{\varepsilon}_{2}=\left[\dot{\varepsilon}_{\mathrm{eq}} \sigma_{\mathrm{eq}}^{1-m}-\varepsilon_{\mathrm{eq}} \sigma_{\mathrm{eq}}^{-m} \dot{\sigma}_{\mathrm{eq}}(m-1)\right] \\
{\left[(1-k) \sigma_{2}^{m-1}-k h\left(\sigma_{1}-h \sigma_{2}\right)^{m-1}\right]} \\
+\varepsilon_{\mathrm{eq}} \sigma_{\mathrm{eq}}^{1-m}\left[(1-k)(m-1) \sigma_{2}^{m-2} \dot{\sigma}_{2}\right. \\
\left.-k h(m-1)\left(\sigma_{1}-h \sigma_{2}\right)^{m-2}\left(\dot{\sigma}_{1}-h \dot{\sigma}_{2}\right)\right]
\end{array}\right.
$$

Let $\dot{\sigma}_{\mathrm{eq}}=w \dot{\varepsilon}_{\mathrm{eq}}$, where $w=d \sigma_{\mathrm{eq}} / d \varepsilon_{\mathrm{eq}}$ is the hardening modulus which can be derived from true stress vs. true strain curves. By eliminating $\dot{\sigma}_{2}$ in $\mathrm{Eq} 16$ (see Appendix for additional details), $\dot{\sigma}_{1}$ can be expressed as

$\dot{\sigma}_{1}=\frac{\left(B_{2} \dot{\varepsilon}_{1}+B_{4} \dot{\varepsilon}_{2}\right) \sigma_{\mathrm{eq}}-B_{1}\left[1-w(m-1) \varepsilon_{\mathrm{eq}} / \sigma_{\mathrm{eq}}\right]\left(\sigma_{1} \dot{\varepsilon}_{1}+\sigma_{2} \dot{\varepsilon}_{2}\right)}{B_{2} \varepsilon_{\mathrm{eq}}}$

where $B_{i}(i=1,2,3,4)$ are

$B_{1}=\frac{1}{g\left(\rho_{\sigma}\right)}(1-k)\left[(1-k) \rho_{\sigma}^{m-2}+k\left(1-h \rho_{\sigma}\right)^{m-2}\left(h^{2}+\rho_{\sigma}^{m-2}\right)\right]$

$$
\begin{aligned}
B_{2}=(m-1) & {\left[(1-k)^{2} \rho_{\sigma}^{m-2}+k h(1-k)\left(1-h \rho_{\sigma}\right)^{m-2}\right.} \\
& \left.\left(h+\rho_{\sigma}^{m-2}\right)+k^{2} h^{2}(h-1)\left(1-h \rho_{\sigma}\right)^{2 m-4}\right]
\end{aligned}
$$

$B_{3}=\left[(1-k) \rho_{\sigma}^{m-2}+k h^{2}\left(1-h \rho_{\sigma}\right)^{m-2}\right]\left[g\left(\rho_{\sigma}\right)\right]^{m-2}$

$B_{4}=k h\left(1-h \rho_{\sigma}\right)^{m-2}\left[g\left(\rho_{\sigma}\right)\right]^{m-2}$

and

$g\left(\rho_{\sigma}\right)=\frac{\sigma_{\mathrm{eq}}}{\sigma_{1}}=\left[(1-k)\left(1+\rho_{\sigma}^{m}\right)+k\left(1-h \rho_{\sigma}\right)^{m}\right]^{1 / m}$

By taking the differential of both sides of Eq 17 we find 


$$
\begin{aligned}
& \Delta \dot{\sigma}_{1}= \\
& \frac{\left(B_{3}+B_{4} \rho_{\varepsilon}\right) g\left(\rho_{\sigma}\right)-B_{1}\left[1-w(m-1) \varepsilon_{\mathrm{eq}} / \sigma_{\mathrm{eq}}\right]\left(1+\rho_{\sigma} \rho_{\varepsilon}\right)}{B_{2} \varepsilon_{\mathrm{eq}}} \sigma_{1} \Delta \dot{\varepsilon}_{1}
\end{aligned}
$$

As shown by Min et al. (Ref 30$)$, there is a zero-extension direction with respect to the deformation on the LHS of the FLD (for many sheet metal alloys) according to the zeroextension hypothesis proposed by Hill (Ref 25). The critical hardening modulus, $w_{\mathrm{cr}}$, which corresponds to localized necking and is used to solve for the forming limit strains, can be computed by substituting Eq 4 and the first of Eq 6 into Eq 23

$w_{\mathrm{cr}}=\frac{\sigma_{\mathrm{eq}}}{\varepsilon_{\mathrm{eq}}(m-1)}\left[1-\frac{\left(B_{3}+B_{4} \rho_{\varepsilon}\right) g\left(\rho_{\sigma}\right)-B_{2} \varepsilon_{\mathrm{eq}}\left(1+\rho_{\varepsilon}\right)}{B_{1}\left(1+\rho_{\sigma} \rho_{\varepsilon}\right)}\right]$

If the necking band of the sheet specimen is normal to the major strain direction, e.g., on the RHS of the FLD, then $w_{\text {cr }}$ can be computed by substituting Eq 4 and the second equation of Eq 6 into Eq 23. This gives

$w_{\mathrm{cr}}=\frac{\sigma_{\mathrm{eq}}}{\varepsilon_{\mathrm{eq}}(m-1)}\left[1-\frac{B_{3} g\left(\rho_{\sigma}\right)-B_{2} \varepsilon_{\mathrm{eq}}}{B_{1}}\right]$

From the strain energy principle, (see Eq A4)

$\sigma_{\mathrm{eq}} \varepsilon_{\mathrm{eq}}=\sigma_{1} \varepsilon_{1}+\sigma_{2} \varepsilon_{2}$

By employing Eq 14 and 21, $\varepsilon_{\text {eq }}$ can be expressed as

$\varepsilon_{\mathrm{eq}}=\frac{\sigma_{1} \varepsilon_{1}+\sigma_{2} \varepsilon_{2}}{\sigma_{\mathrm{eq}}}=\left(1+\rho_{\sigma} \rho_{\varepsilon}\right) \frac{\varepsilon_{1}}{g\left(\rho_{\sigma}\right)}$

If power law hardening is assumed

$\sigma_{\mathrm{eq}}=K \varepsilon_{\mathrm{eq}}^{n}$

then the hardening modulus can be calculated as

$w=K n \varepsilon_{\mathrm{eq}}^{n-1}$

An analytical model for the LHS of the FLD can be deduced by substituting Eq 27-29 into Eq 24 . This yields $\varepsilon_{1}^{*}$, which is the major limit strain corresponding to localized necking

$\varepsilon_{1}^{*}=g\left(\rho_{\sigma}\right) \frac{\left(B_{3}+B_{4} \rho_{\varepsilon}\right) g\left(\rho_{\sigma}\right)+B_{1}\left(1+\rho_{\sigma} \rho_{\varepsilon}\right)[n(m-1)-1]}{B_{2}\left(1+\rho_{\sigma} \rho_{\varepsilon}\right)\left(1+\rho_{\varepsilon}\right)}$

For the RHS of the FLD, $\varepsilon_{1}^{*}$ can be deduced by substituting Eq 27-29 into Eq 25.

$\varepsilon_{1}^{*}=g\left(\rho_{\sigma}\right) \frac{B_{3} g\left(\rho_{\sigma}\right)-B_{1}[1-n(m-1)]}{B_{2}\left(1+\rho_{\sigma} \rho_{\varepsilon}\right)}$

When considering an isotropic case and the von Mises yield criterion, namely, $r_{0}=r_{90}=1$ and, $m=2$ the $B_{i}(i=1-4)$ in $\mathrm{Eq} 30$ and 31 become $B_{1}=\frac{3}{4 g\left(\rho_{\sigma}\right)}, \quad B_{2}=\frac{3}{4}, \quad B_{3}=1$, $B_{4}=1 / 2$. Equations 30 and 31 then reduce to, respectively,

$\varepsilon_{1}^{*}=\frac{n}{1+\rho_{\varepsilon}}$ $\varepsilon_{1}^{*}=\frac{3 \rho_{\varepsilon}^{2}+n\left(2+\rho_{\varepsilon}\right)^{2}}{2\left(2+\rho_{\varepsilon}\right)\left(1+\rho_{\varepsilon}+\rho_{\varepsilon}^{2}\right)}$

which are the same as those reported by Zhu et al. (Ref 33) who validated their model for various sheet alloys using the von Mises yield criterion and in-plane isotropy at RT. However, the models deduced in the present paper (Eq 30 and 31) consider both high-order yield criterion and planar anisotropy, which is more generalized than the models by Zhu et al. (Ref 33) and can be applied to more materials. We also note that the other studies have assumed various hardening models in the course of developing theoretical methods for FLD prediction. A notable recent example is the use of the Voce hardening model by Li et al. (Ref 22) for FLD prediction of 5182 aluminum subject to preform annealing.

For a rate-dependent material, the following law can be employed

$\sigma_{\mathrm{eq}}=K \varepsilon_{\mathrm{eq}}^{n} \dot{\varepsilon}_{\mathrm{eq}}^{M}$

where $M$ is the strain rate sensitivity. Corresponding expressions for $\varepsilon_{1}^{*}$ can be deduced according to the method introduced by Min et al. (Ref 53).

Up to this point, a generalized localized necking criterion based upon Eq 30 and 31 for metal sheet alloys has been developed based on the Storen and Rice (Ref 32) vertex theory and the Barlat-Lian orthotropic yield criterion. When predicting the FLCs of sheet metal alloys that follow a power law hardening equation (Eq 28), the $n$ and $r$ values in the $0^{\circ}$ and $90^{\circ}$ orientations and the $m$ value are needed as inputs. The former can be obtained from uniaxial tensile tests, and the latter can be obtained from references or experiments. In addition, the fracture mode of the metal sheet alloy, especially in the negative minor-strain region, should be noted. If fracture follows the Hill's zero-extension hypothesis (Ref 25), Eq 30 and 31 are used to predict the FLC on the LHS and RHS, respectively. If fracture follows the zero-angle necking hypothesis proposed by Min et al. (Ref 53), Eq 31 is used to predict both sides of the FLC.

\section{Experimental Validation}

The material used to validate the theoretical developments in the preceding sections is $\mathrm{Mg}$ ZEK100 rolled sheet in the F temper (as-fabricated), with a $1.5 \mathrm{~mm}$ thickness, and a hardness of $\sim 55$ HRF. The chemical content of the alloy, which is listed in Table 1, consists of $\mathrm{Zn}$ (for strength), $\mathrm{Nd}$ (for texture control), $\mathrm{Zr}$ (for grain size refinement), and trace amounts of Ce and La. The microstructure of the starting material, which is shown in Fig. 2, exhibits numerous twins from sheet manufacturing.

\subsection{Uniaxial Tensile Tests}

Tensile specimens were water jet cut at $0^{\circ}, 45^{\circ}$, and $90^{\circ}$ to the RD. The dimensions are shown in Fig. 3. The specimens were annealed at $500{ }^{\circ} \mathrm{C}$ for $15 \mathrm{~min}$ to remove the "cold work". The annealing process was carried out in an electric furnace which was filled with argon gas to protect the tensile specimens from oxidization. After annealing, the specimens 
Table 1 Chemical composition of Mg ZEK100 sheet (wt.\%)

\begin{tabular}{cccccc}
\hline Mg & Zn & Zr & Nd & Ce & La \\
\hline Bal & 1.34 & 0.230 & 0.182 & 0.008 & 0.001 \\
\hline
\end{tabular}

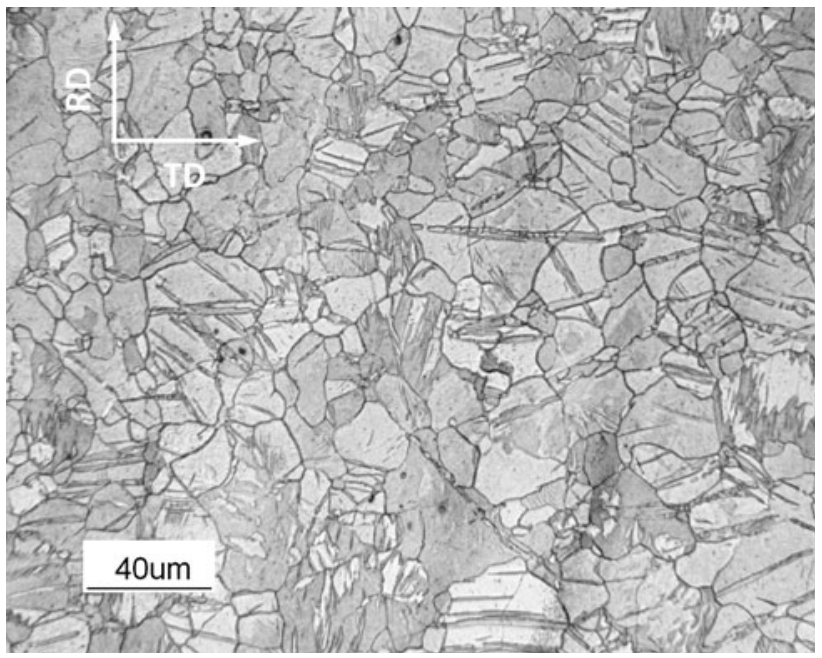

Fig. 2 Optical micrograph of Mg ZEK100 sheet in the F temper. The vertical direction is along the $0^{\circ}$ or rolling direction (RD), and the horizontal direction is the $90^{\circ}$ or transverse direction (TD)

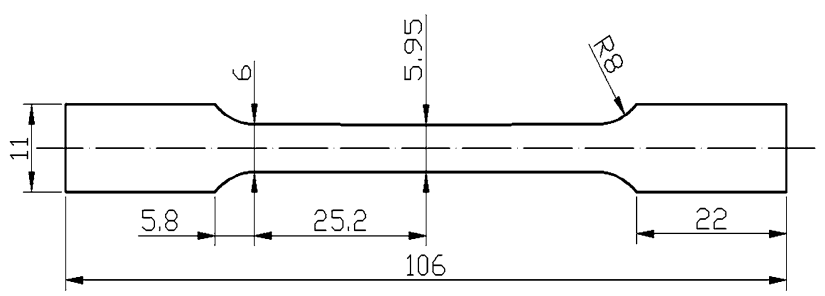

Fig. 3 Illustration showing the dimensions of the Mg ZEK100-O tensile specimens (all values in $\mathrm{mm}$ )

were air cooled. The annealed material is hereinafter denoted as ZEK100-O and its microstructure is shown in Fig. 4.

Three tensile specimens in both $0^{\circ}$ and $90^{\circ}$ orientations were quasi-statitically elongated at a strain rate of $0.005 / \mathrm{s}$ and at RT until fracture, and single specimens in $0^{\circ}, 45^{\circ}$, and $90^{\circ}$ orientations were elongated to $10 \%$ strain to determine the Lankford coefficients $r_{0}, r_{45}$, and $r_{90}$, which were used to calculate the averaged $r$ value $(\bar{r})$. To facilitate determination of the $r$ value in each orientation, five locations were marked with lines drawn on each tensile specimen, and the cross-sectional dimensions were measured at each of these locations before and after elongation to an engineering strain of $10 \%$. The $r$ value in each orientation was calculated as the average of the five values via,

$r=\frac{\varepsilon_{2}}{\varepsilon_{3}}=\frac{\ln \left(w_{\mathrm{i}} / w_{\mathrm{f}}\right)}{\ln \left(t_{\mathrm{i}} / t_{\mathrm{f}}\right)}$

where $w_{\mathrm{i}}$ and $t_{\mathrm{i}}$ are the initial width and thickness, respectively, at each location on the specimens before elongation; $w_{\mathrm{f}}$ and $t_{\mathrm{f}}$ are the final width and thickness, respectively, at each location on the specimens after elongation. All tensile

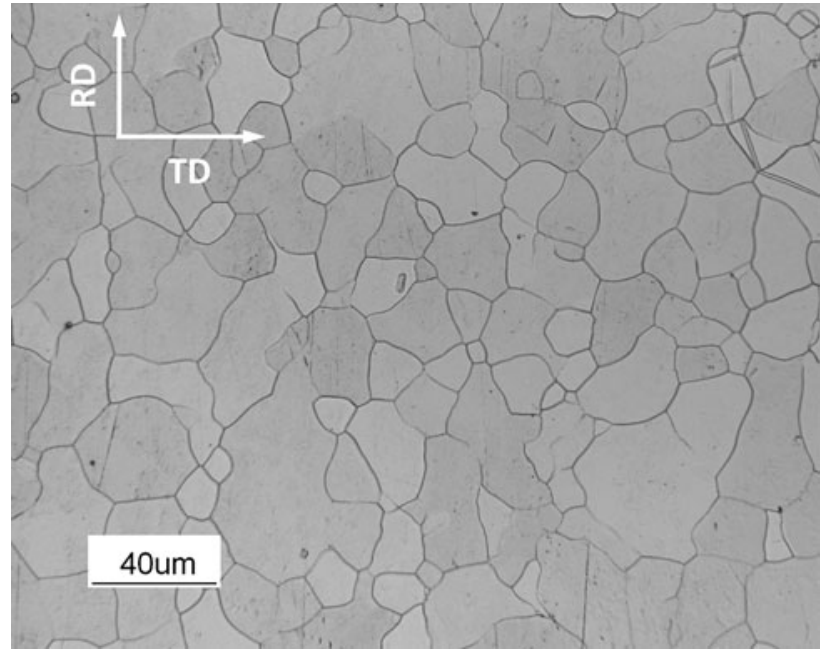

Fig. 4 Optical micrograph of Mg ZEK100-O sheet. The vertical direction is along the $0^{\circ}$ or rolling direction (RD), and the horizontal direction is the $90^{\circ}$ or transverse direction (TD)

tests were performed on an Instron 5582 universal tensile testing machine at RT. An extensometer with a $25 \mathrm{~mm}$ gage length was used to measure the strain and the crosshead speed was $10 \mathrm{~mm} / \mathrm{min}$. All Mg ZEK100-O specimens exhibit a very brief period of diffuse necking followed by an even shorter period of localized necking and fracture.

\subsection{Forming Limit Tests}

The specimens for the forming limit tests were cut at $0^{\circ}$ and $90^{\circ}\left(45^{\circ}\right.$ specimens were precluded since the axes of stresses are not coincident with the principal coordinate system) with respect to the $\mathrm{RD}$ and are hereinafter referred as the RD specimens and the TD specimens, respectively. The dimensions of the specimens are shown in Fig. 5. The lower left inset figure shows a sampling of the circle grids used to measure strain. The circular elements in each grid pattern had a diameter of $2.5 \mathrm{~mm}\left(d_{0}\right)$ and a center-to-center spacing of $3 \mathrm{~mm}$. The overall patterns were laser etched onto one surface of each specimen: these are denoted by the gray regions in each specimen geometry in Fig. 5. For the $180 \mathrm{~mm}$ wide specimen, the grid was arranged in a pattern that followed a cruciform profile in which there were 15 circular elements and 33 circular elements in the short edge direction and in the long edge direction, respectively, as illustrated in Fig. 5. For all remaining specimens, there were 33 circular elements in the length direction. However, there were $17,15,11$, and 5 circular elements along the width direction for specimens with widths of $140,120,80$, and $30 \mathrm{~mm}$, respectively.

The width and depth of each circular element was $\sim 50 \mu \mathrm{m}$ (see Fig. 5) and $\sim 20 \mu \mathrm{m}$, respectively. These dimensions did not lead to damage of the base metal, namely, specimens did not fracture early along the circular elements. The grids were free of distortion even after the $500{ }^{\circ} \mathrm{C}$ heat treatment. The forming limit tests were conducted with the Nakajima test apparatus in the 200 ton capacity press shown in Fig. 6 .

The punch speed was $2 \mathrm{~mm} / \mathrm{s}$. Square Teflon ${ }^{\circledR}$ sheets, with dimensions of $100 \times 100 \mathrm{~mm}^{2}$ and $0.1 \mathrm{~mm}$ thickness, were used as the lubricating medium between the punch and the test specimens. Figure 7(a) shows the bulged specimens that correspond to the specimens shown in Fig. 5. For the narrow specimens (i.e., with a width smaller than $100 \mathrm{~mm}$ ), fracture always occurred at the 


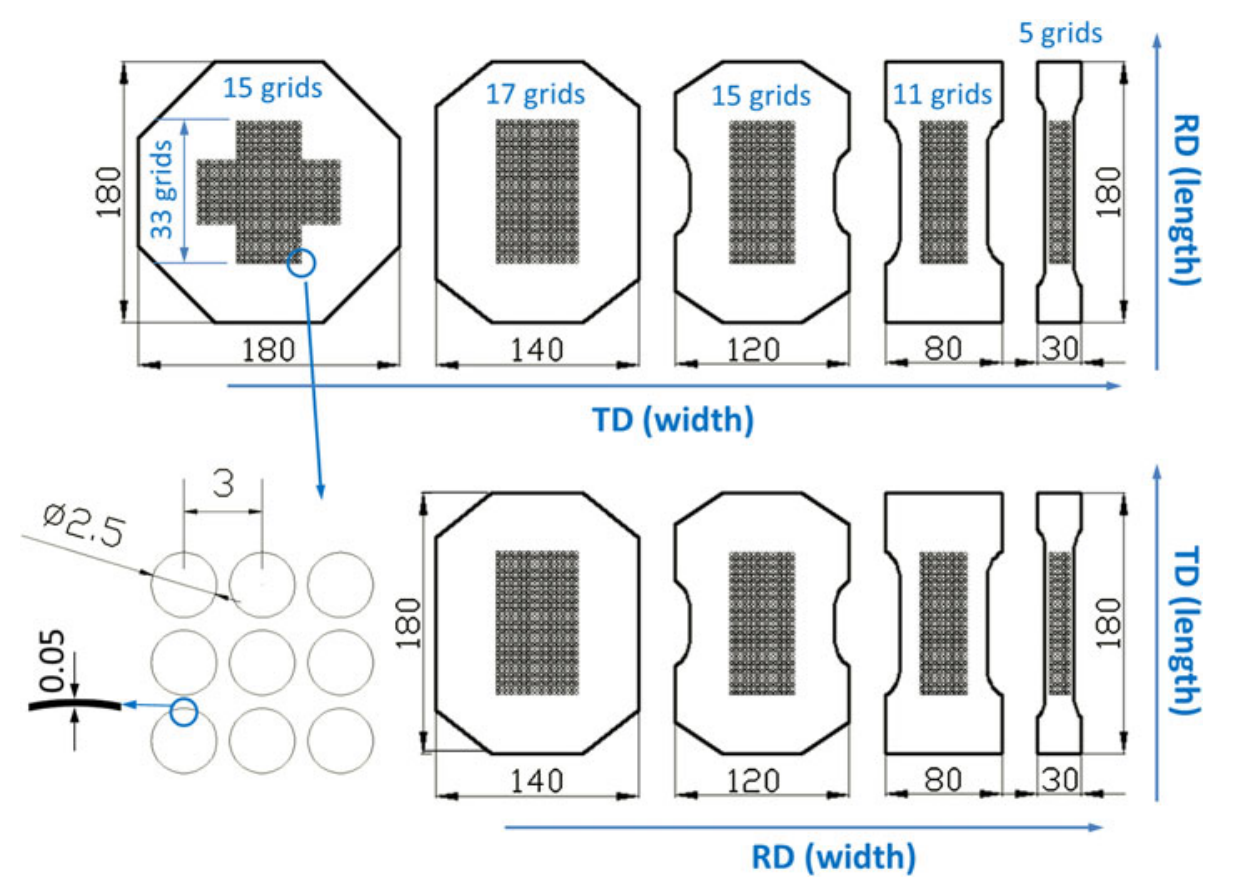

Fig. 5 Illustration for the Nakajima specimen dimensions of Mg ZEK100-O (all dimensions in mm). The dimensions of the circular elements that comprise each grid are shown in the bottom left figure. The vertical direction is along the RD for specimens in the top row and along the TD for specimens in the bottom row

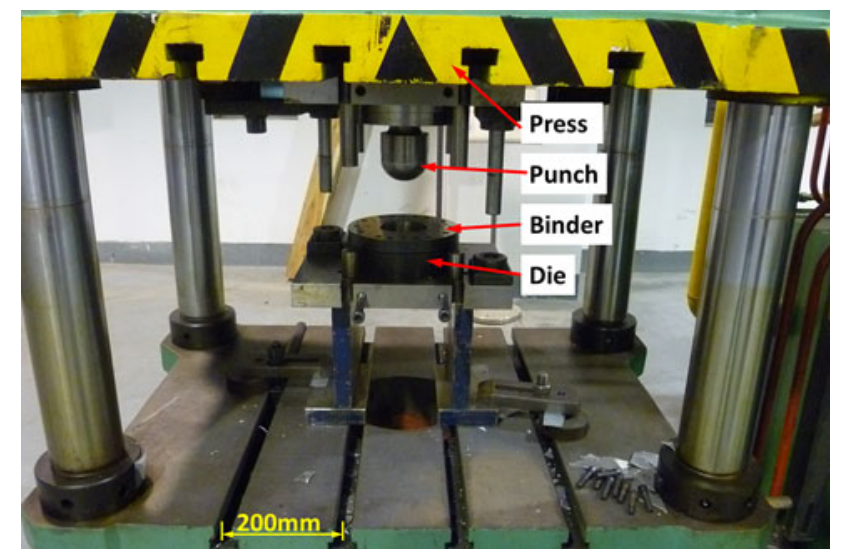

Fig. 6 Shown is the Nakajima test apparatus for testing forming limits of Mg ZEK100-O sheets. The punch diameter was $100 \mathrm{~mm}$. The capacity of the press was 200 tons. The stamping speed for all tests was $2 \mathrm{~mm} / \mathrm{s}$

drawbeads or die radius even though the binder force was decreased in proportion to the specimen width (see Fig. 7a). This may have been due to the poor (combined) drawing and bending response of the $\mathrm{Mg} \mathrm{ZEK} 100-\mathrm{O}$ material at RT. To address this issue, the narrow specimens (see Fig. 7b) were elongated on a tensile machine to fracture to obtain the limit strain data with negative minor strains. During deformation, the circular elements became ellipses with a major axis length of $d_{1}$ and minor axis length of $d_{2}$ (see Fig. 7c). Major and minor strains were then calculated via

$\varepsilon_{i}=\ln \left(d_{i} / d_{0}\right), \quad i=1,2$

The circular elements close to the fracture were regarded as critical elements, and the strains were measured along the RD and TD (see Fig. 7c).

\section{Results and Discussion}

\subsection{Mg ZEK100-0 Mechanical Properties}

True stress versus true strain curves of the Mg ZEK100-O sheet material cut along the three orientations are shown in Fig. 8. The material shows an obvious YPE in the TD, an observation that has previously been reported for Mg ZEK100$\mathrm{O}$ by Min et al. (Ref 54). Barnett et al. (Ref 55) investigated Lüders phenomenon during compression of extruded Mg AZ31 (along the extrusion direction) with a fine (5-15 $\mu \mathrm{m})$ grain size and attributed it to deformation twinning rather than dislocation glide. It is believed that it is also responsible for the YPE shown in Fig. 8. The work hardening exponent $n$ values for $\mathrm{Mg}$ ZEK100-O resulted from fits of Eq 28 to the flow data for the $0^{\circ}$ and $90^{\circ}$ specimens in the 0.02-0.16 and 0.02-0.23 strain ranges, respectively. The $n$ values, the $R^{2}$ values, and the $r$ values, are summarized in Table 2 , where each value is averaged using data from the three specimen sets.

From Table 2, it can be seen that the Mg ZEK100-O sheets show different $n$ values and $r$ values in the $0^{\circ}$ and $90^{\circ}$ orientations, which suggests in-plane anisotropy. The average $r$ value $(\bar{r})$ from

$\bar{r}=\left(r_{0}+2 r_{45}+r_{90}\right) / 4$

is 0.79 , which will be used as an input when calculating forming limit strains without consideration of in-plane anisotropy.

\subsection{Forming Limits}

The necking band of the Mg ZEK100-O sheet material is always normal to the major strain direction. This is seen from all of the fractured RD and TD specimens in Fig. 7. Hence, Hill's zero-extension hypothesis is not applicable. Rather, it follows the 


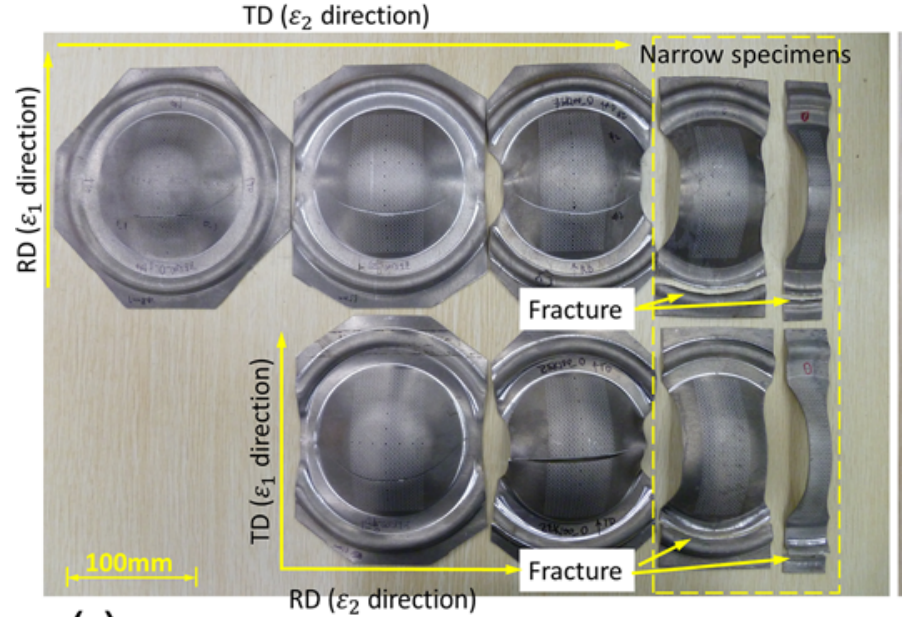

(a)

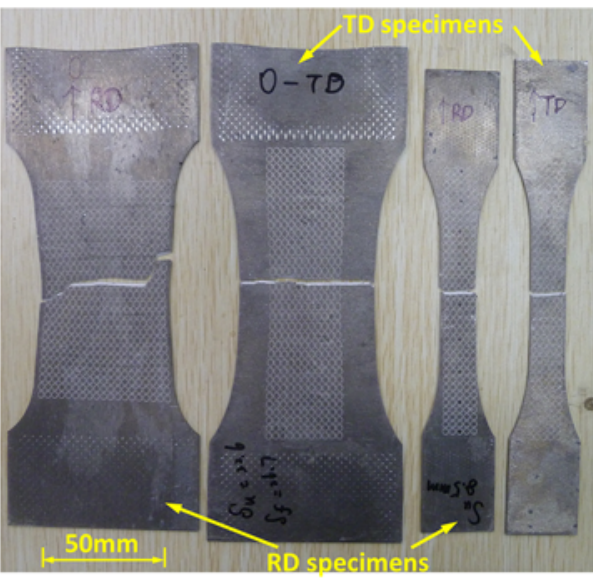

(b)

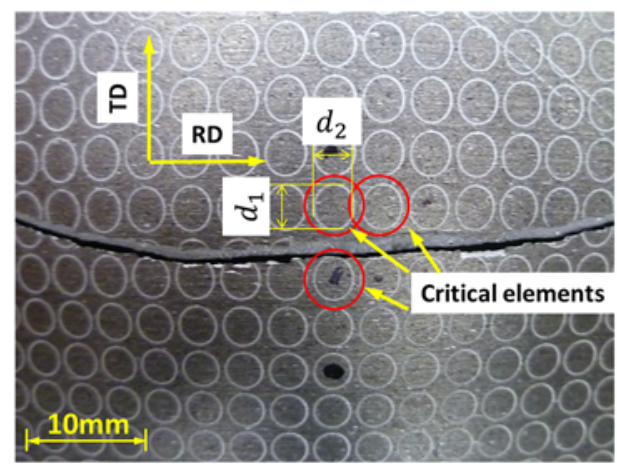

(c)

Fig. 7 (a) Bulged ZEK100-O specimens. Here, $\varepsilon_{1}$ and $\varepsilon_{2}$ indicate major and minor strains, respectively. (b) Deformed ZEK100-O narrow specimens (with width smaller than $100 \mathrm{~mm}$ ). (c) Illustration for critical elements (i.e., within 0.5-1 mm of fracture) on a bulged TD specimen with a width of $140 \mathrm{~mm}$, namely, the specimen on the lower left of (a). The major axis length and minor axis length of the critical element are $d_{1}$ and $d_{2}$, respectively

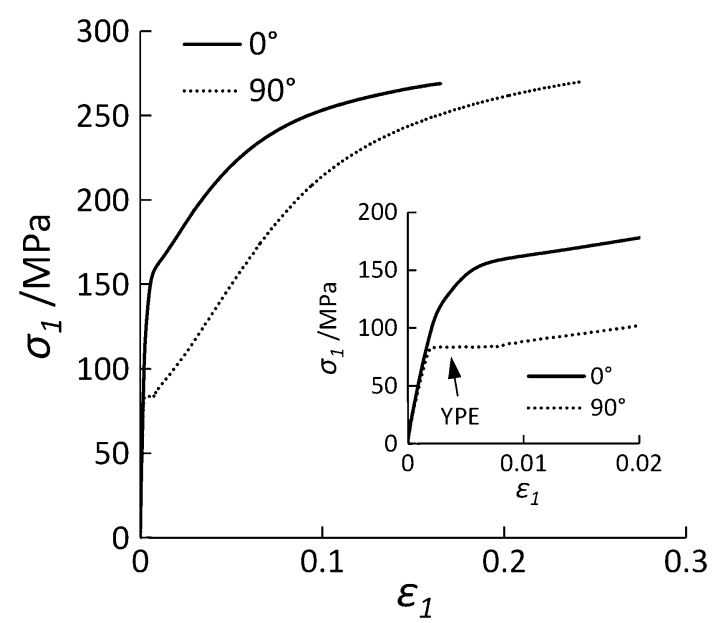

Fig. 8 True stress $\left(\sigma_{1}\right)$ vs. true strain $\left(\varepsilon_{1}\right)$ curves of Mg ZEK100$\mathrm{O}$ sheets in the $0^{\circ}$ and $90^{\circ}$ orientations. The inset shows the yield point elongation (YPE) in a $90^{\circ}$ tensile specimen

hypothesis of zero-angle necking in Min et al. (Ref 53) where it is shown that the Hill's zero-extension hypothesis will overestimate the forming limit strains on the LHS of the FLD. Therefore, Eq 31 is employed to predict the forming limit strains on both sides of the FLD of the Mg ZEK100-O sheet.
4.2.1 Forming Limit Diagram in the RD. For the RD specimens (see Fig. 5), the major strain $\left(\varepsilon_{1}\right)$ and minor strain $\left(\varepsilon_{2}\right)$ directions are along the RD and the transverse direction (TD), respectively. Note that the order ( $m$ value) of the BarlatLian yield criterion for Mg ZEK100-O alloy is not known, and it cannot be obtained from the literature. Therefore, comparisons between the experimentally determined forming limits and predictions from the Zhu et al. (Ref 33) model and our analytical model are presented in Fig. 9. A range of yield criterion orders $(\mathrm{m})$ is examined. This enabled determination of which model resulted in the closest agreement with the experimental results. Note that $\varepsilon_{1}$ and $\varepsilon_{2}$ are denoted as $\varepsilon_{\mathrm{RD}}$ and $\varepsilon_{\mathrm{TD}}$, respectively. The $n$ value and $r_{0}$ and $r_{90}$ values used in Eq 31 for the FLC calculation are taken from Table 2. The comparisons in Fig. 9 suggest that the Zhu et al. (Ref 33) model, which considers the von Mises yield criterion and isotropy, gives predictions that are significantly in error compared with experimental data; however, an order of 12 in the yield criterion of Eq 8 leads to the smallest error between the analytical model in this paper and the experimental data (the error of the predicted limit strain data relative to the experimental data is within $4 \%$ ). When $m=6$ and $m=8$, which are, respectively, recommended for $\mathrm{BCC}$ and FCC materials, the theoretical predictions overestimate the forming limits in both the LHS and RHS and the errors relative to experimental data reach $\sim 32 \%$ and $\sim 16 \%$ at the uniaxial tensile and biaxial 
Table 2 Mechanical properties of the Mg ZEK100-O sheets. The closer the fit is to the data points, the closer the $R^{2}$ value will be to 1

\begin{tabular}{llll}
\hline Parameters & $\mathbf{0}^{\circ}$ & $\mathbf{4 5}^{\circ}$ & $\mathbf{9 0}^{\circ}$ \\
\hline$n$ value & 0.162 & $\ldots$ & 0.430 \\
$R^{2}$ value & 0.992 & $\ldots$ & 0.988 \\
$r$ value & 0.75 & 0.94 & 0.52 \\
\hline
\end{tabular}

states, respectively. For $m=10$, the prediction is very close to the experimental forming limit strain data on the RHS, while on the LHS, it overestimates the forming limits by $\sim 9 \%$ at the uniaxial tensile state. For $m>12$, the predicted limit strains are underestimated especially on the RHS of the FLD, and the error relative to experimental data at the balanced biaxial tensile state reaches $\sim 6 \%$. For $\mathrm{Al}$ or steel sheets, the FLC on the RHS typically increases with increasing minor strain suggesting good stretchability. Alternatively, the FLC on the RHS in Fig. 9 for $\mathrm{Mg}$ ZEK100-O decreases with increasing minor strain which suggests poor stretchability relative to $\mathrm{Al}$ and steel.

Figure 10 shows another comparison of the analytical model predictions based upon in-plane isotropy and the Barlat-Lian anisotropic yield criteria with experimental data. The dashed line corresponds to thickness anisotropy only, i.e., it employs $r_{0}$ and $r_{90}$ both equal to $0.79(\bar{r})$, calculated from Eq 37 . The solid line shows the predicted FLC considering in-plane anisotropy, namely, the applied yield criterion is orthotropic, and it uses the measured $r_{0}$ and $r_{90}$ in Table 2. The order $m$ used in both predicted FLCs is 12. Clearly, the FLC prediction based on the orthotropic yield criterion is in better agreement with experimental data. The prediction based on the planar-isotropic yield criterion gives an overestimated FLC, especially on the LHS of the FLD, and the error reaches $\sim 6 \%$ at the uniaxial tensile state.

4.2.2 Forming Limit Diagram in the TD. For the TD specimens, the $\varepsilon_{1}$ and $\varepsilon_{2}$ directions are consistent with the TD and $\mathrm{RD}$, respectively; hence, $\varepsilon_{1}$ and $\varepsilon_{2}$ in the conventional FLD are denoted as $\varepsilon_{\mathrm{TD}}$ and $\varepsilon_{\mathrm{RD}}$, respectively. As Fig. 8 shows, material in the TD exhibits YPE and with an $n$ value as high as 0.43 . The predicted FLC in the TD using this $n$ value is indicated by the dotted line in Fig. 11, in which a comparison of forming limit data in both the RD and the TD is also shown, and the point where the FLC in the RD intersects with the FLC in TD indicates the forming limit strains in the balanced biaxial tensile state. The predicted FLC in the TD is clearly much higher than the experimental results. The strain range used to fit the $n$ value is 0.02 to 0.23 ; this includes the sigmoidal hardening region, the strain range from 0.01 to $\sim 0.1$, on the true stress versus true strain curve in Fig. 8. As Wu et al. (Ref 56) stated, a twinning dominated deformation mechanism results in the sigmoidal hardening on the true stress versus true strain curve for Mg AZ31 alloy sheet. However, a dislocation slip mechanism gives rise to power law hardening as shown in the strain range from $\sim 0.1$ to 0.23 for the TD tensile specimen and in the strain range from 0.02 to 0.18 for the RD tensile specimen (see Fig. 8). To exclude the influence of the YPE and sigmoidal hardening associated with twinning dominated deformation, a $0.15-0.23$ strain range was used to refit the $n$ value in the TD specimen. This gives an $n$ value of 0.183 , and the $R^{2}$ value is 0.999 , which is much higher than the $R^{2}$ value (0.988) in Table 2 for the fit over a 0.02-0.23 strain range. This suggests that power law hardening more accurately describes

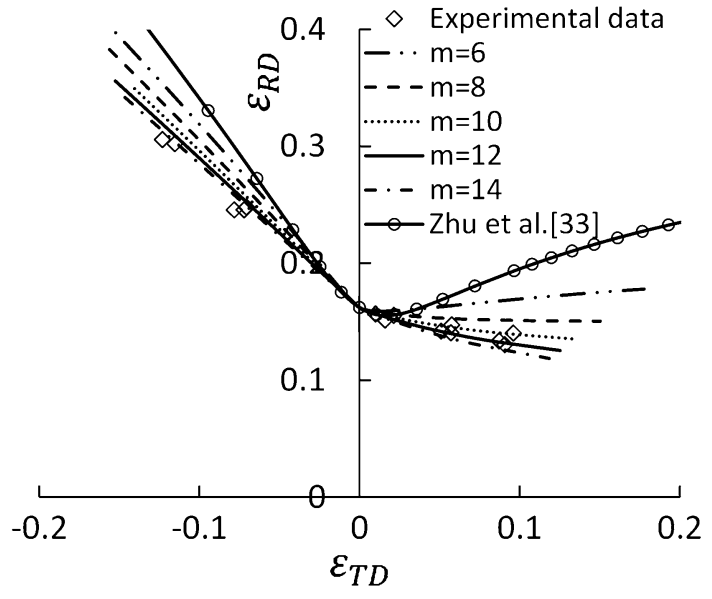

Fig. 9 Comparison between the experimental forming limits of $\mathrm{Mg}$ ZEK100-O sheets (based on RD specimens) from the theoretical predictions from the Zhu et al. (Ref 33) model and the analytical method in this paper with different orders ( $m$ values) for the Barlat-Lian yield criterion in Eq 8. Here $r_{0}=0.75, r_{90}=0.52$

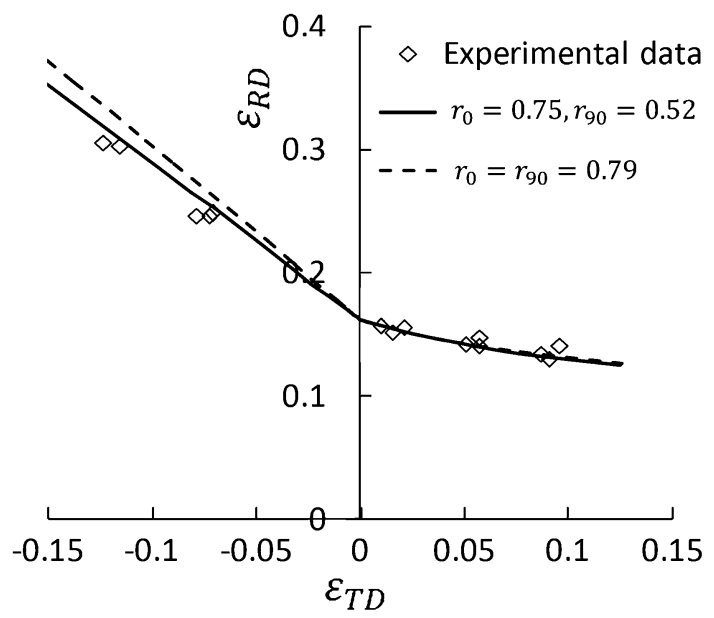

Fig. 10 Comparison of the prediction results between models based on the in-plane isotropic yield criterion (dashed line) and the orthotropic Barlat-Lian yield criterion (solid line)

the hardening behavior in the strain range $0.15-0.23$ relative to the strain range $0.02-0.23$. The predicted FLC in the TD using this new $n$ value is shown in Fig. 11 as indicated by the dashed line. It can be observed that the dashed FLC is much closer to the experimental data in the TD.

For materials exhibiting sigmoidal hardening due to twinning dominated deformation, care should be taken when choosing the strain range over which to compute the $n$ value and then using the $n$ value to evaluate formability of $\mathrm{Mg}$ alloys sheets. If the strain range used to fit the $n$ value includes the sigmoidal hardening region, a high $n$ value will be obtained which does not reflect the real formability of the material. In addition, it should be noted that the deduced analytical model (Eq 30 and 31) for forming limits based on the vertex theory and orthotropic high-order yield criterion is applicable to many sheet metals appropriate for automotive component forming and hence it is not limited to Mg ZEK100-O alloy sheets. Examples are various aluminum alloys $(\operatorname{Ref} 22,57,58)$ and 


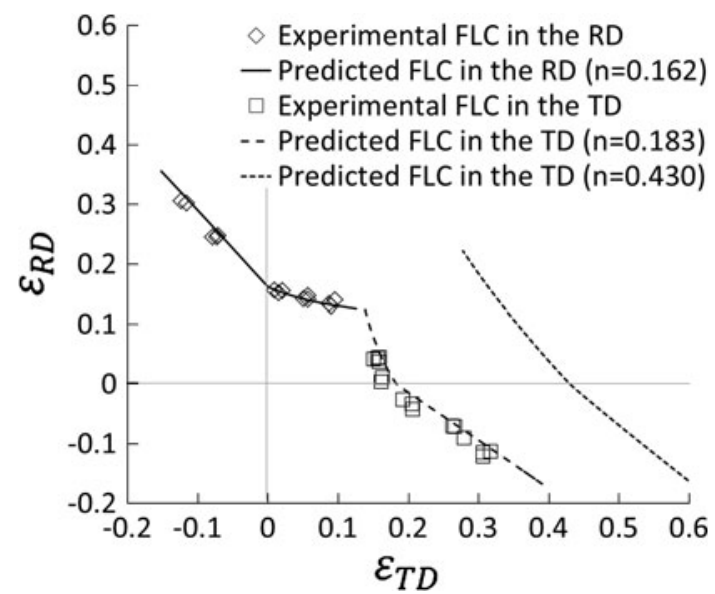

Fig. 11 FLD showing forming limits of Mg ZEK100-O sheets in both the RD and the TD. Dashed and dotted lines show, respectively, the predicted FLC using the new $n$ value fitted excluding the sigmoidal hardening region and the $n$ value fitted including the sigmoidal hardening region on the true stress vs. true strain curve. Here, $m=12, r_{0}=0.75$ and $r_{90}=0.52$ for all predicted FLCs

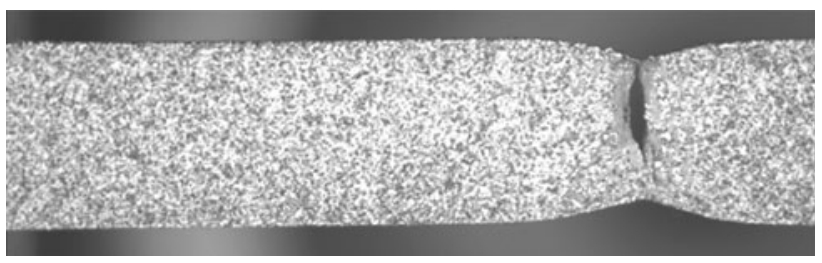

Fig. 12 Fully martenstic steel (900 grade) showing ductile rupture in a quasi-static, room temperature tensile test (Ref 61$)$. The tensile axis is along the horizontal

steels (Ref 59,60). However, there are some notable exceptions. If the material undergoes diffuse necking followed by ductile rupture with no obvious localized necking, then the present theory should not be used. A poignant example is 900 grade fully martensitic steel which undergoes a ductile rupture process with no obvious localized neck. This is shown in Fig. 12. As discussed in Savic et al. (Ref 61), 1300 grade fully martensitic steel (for example) does display a localized neck and the present theoretical approach to FLD prediction can indeed be applied.

\section{Conclusions}

(1) A new analytical method for strain-based FLD prediction, which combines the Storen and Rice (Ref 32) vertex theory, the Barlat-Lian high-order yield criterion (Ref 37) including in-plane anisotropy, and a hardening law, was developed and applied to an Mg ZEK100-O alloy (Zn1.34Zr0.23Nd0.182, wt.\%). The method does not rely on assumptions about pre-existing defects, requires only minimal experimental inputs ( $r$ values, $n$ value, $m$ value, fracture type). The predicted FLDs are in close agreement with experimentally measured FLDs (based upon the well-known Nakajima test) at RT. The method is by no means limited to $\mathrm{Mg}$ alloys since it can be readily applied to predict FLDs in other ferrous and non-ferrous sheet materials.

(2) The analytical method for strain-based FLD prediction detailed in this report is summarized as follows:

(a) Failure of the sheet material of interest must occur via localized necking followed by fracture. This can occur after a period of diffuse necking (such as occurs in various sheet steels), or, it may be the only obvious necking process prior to fracture (such as 1300 grade martensitic steel or press hardened boron steel). If the material undergoes diffuse necking followed by ductile rupture with no localized necking (as occurs, for example, in 900 grade martensitic steel), then the present theory should not be used (see Hosford and Caddell (Ref 21) for the distinction between diffuse and localized necking).

(b) Obtain $n$ values (work hardening exponent) and $r$ values (Lankford coefficients) in the $0^{\circ}$ and $90^{\circ}$ orientations via uniaxial tensile tests or from tabulated values.

(c) Obtain the $m$ value (i.e. the order in Barlat-Lian yield criterion (Ref 37)) from references or experiments. Suggested values (from the following reliable literature sources in the reference list below: Barlat and Lian (Ref 37) and Hosford (Ref 35)) are 6 and 8 for steel (BCC) and aluminum (FCC) alloys, respectively, and 12 for magnesium (HCP) alloys.

(d) Check the fracture type of the tensile specimens. If the fracture follows Hill's zero-extension hypothesis (Ref 25), where the normal direction of the necking band in the sheet plane makes an angle with the major strain direction (or tensile direction), then Eq 30 and 31 are used to predict the FLC on both the LHS and the right-hand side (RHS), respectively, of the FLD. If the fracture follows the zero-angle hypothesis (Ref 53), where the normal direction of the necking band in the sheet plane is always parallel with the major strain direction, then Eq 31 is used to predict the FLC on both the LHS and RHS.

(3) The analytical method for FLD prediction was validated against the experimentally derived FLDs for $\mathrm{Mg}$ ZEK100-O sheet in the RD only. This material exhibits a very brief period of diffuse necking followed by rapid localized necking and fracture in RT, quasi-static tensile tests. The $m$ value in the Barlat-Lian yield criterion (Ref 37) which gives the closest agreement with experimental data for Mg ZEK100-O is 12 .

(4) The Hill's zero-extension hypothesis (Ref 25) on the negative minor-strain region does not accurately account for the necking mode of the Mg ZEK100-O alloy sheets. Rather, the Mg ZEK100-O alloy sheet necking mode is accurately described by the zero-angle necking hypothesis (Ref 53). Hence, the theoretical approach to FLD prediction detailed in this report is applicable to both sides of the Mg ZEK100-O FLD. 
(5) The analytical method in the present paper shows much better agreement with experimental FLD data compared with the theoretical model of Zhu et al. (Ref 33). Consideration of orthotropic plasticity enables the analytical model to be in close accord with experimental data. However, when orthotropic plasticity is not considered, the model overestimates the forming limits for $\mathrm{Mg}$ ZEK $100-O$ by $\sim 6 \%$ at the uniaxial tensile state on the LHS of FLD.

(6) The YPE exhibited by Mg ZEK100-O specimens with a $90^{\circ}$ orientation in uniaxial tension, and the almost sigmoidal hardening beyond the YPE in the TD, and high work hardening exponent or $n$ value of $\sim 0.43$ (for the TD only), results in unrealistically high formability prediction, and leads to overestimation of forming limits. A new $n$ value resulting from a fit of the power law hardening model in the 0.15-0.23 strain range, which excludes the influence of the YPE, enables the predicted results to agree well with the experimental forming limit data for Mg ZEK100-O.

(7) The present analytical method for strain-based FLD prediction would require a modification to the material constitutive model if either forming at temperatures higher than RT were required or power law hardening is insufficient to describe the flow response of the sheet material.

\section{Acknowledgments}

The authors are grateful to Drs. A.K. Sachdev and M.W. Verbrugge for their thorough review of this manuscript.

\section{Appendix: Derivation of Eq 17}

Rearranging Eq 12 yields

$$
\left\{\begin{array}{c}
\sigma_{\mathrm{eq}}^{m} \dot{\varepsilon}_{1}=\sigma_{\mathrm{eq}} \dot{\varepsilon}_{\mathrm{eq}}\left[1-w(m-1) \varepsilon_{\mathrm{eq}} / \sigma_{\mathrm{eq}}\right] \\
{\left[(1-k) \sigma_{1}^{m-1}+k\left(\sigma_{1}-h \sigma_{2}\right)^{m-1}\right]} \\
+\sigma_{\mathrm{eq}} \varepsilon_{\mathrm{eq}}(m-1) \\
\left\{\left[(1-k) \sigma_{1}^{m-2}+k h\left(\sigma_{1}-h \sigma_{2}\right)^{m-2}\right] \dot{\sigma}_{1}\right. \\
\left.\quad-k h\left(\sigma_{1}-h \sigma_{2}\right)^{m-2} \dot{\sigma}_{2}\right\} \\
\sigma_{\mathrm{eq}}^{m} \dot{\varepsilon}_{2}=\sigma_{\mathrm{eq}} \dot{\varepsilon}_{\mathrm{eq}}\left[1-w(m-1) \varepsilon_{\mathrm{eq}} / \sigma_{\mathrm{eq}}\right] \\
{\left[(1-k) \sigma_{2}^{m-1}+k h\left(\sigma_{1}-h \sigma_{2}\right)^{m-1}\right]} \\
+\sigma_{\mathrm{eq}} \varepsilon_{\mathrm{eq}}(m-1) \\
\left\{-k h\left(\sigma_{1}-h \sigma_{2}\right)^{m-2} \dot{\sigma}_{1}\right. \\
\left.+\left[(1-k) \sigma_{2}^{m-2}+k h^{2}\left(\sigma_{1}-h \sigma_{2}\right)^{m-2}\right] \dot{\sigma}_{2}\right\}
\end{array}\right.
$$

(Eq A1)

Multiply the first equation in Eq A1 by $\left[(1-k) \sigma_{2}^{m-2}+\right.$ $\left.k h^{2}\left(\sigma_{1}-h \sigma_{2}\right)^{m-2}\right]$, and the second equation in Eq A1 by $k h\left(\sigma_{1}-h \sigma_{2}\right)^{m-2}$. Adding the resulting expressions, followed by elimination of $\dot{\sigma}_{2}$ gives

$$
\begin{aligned}
& \left\{\left[(1-k) \sigma_{2}^{m-2}+k h^{2}\left(\sigma_{1}-h \sigma_{2}\right)^{m-2}\right] \dot{\varepsilon}_{1}+k h\left(\sigma_{1}-h \sigma_{2}\right)^{m-2} \dot{\varepsilon}_{2}\right\} \sigma_{\mathrm{eq}}^{m} \\
& =\sigma_{\mathrm{eq}} \dot{\varepsilon}_{\mathrm{eq}}\left[1-w(m-1) \varepsilon_{\mathrm{eq}} / \sigma_{\mathrm{eq}}\right] \\
& \left\{\left[(1-k) \sigma_{1}^{m-1}+k\left(\sigma_{1}-h \sigma_{2}\right)^{m-1}\right]\right. \\
& {\left[(1-k) \sigma_{2}^{m-2}+k h^{2}\left(\sigma_{1}-h \sigma_{2}\right)^{m-2}\right]} \\
& \left.+\left[(1-k) \sigma_{2}^{m-1}-k h\left(\sigma_{1}-h \sigma_{2}\right)^{m-1}\right]\left[k h\left(\sigma_{1}-h \sigma_{2}\right)^{m-2}\right]\right\} \\
& +\sigma_{\mathrm{eq}} \varepsilon_{\mathrm{eq}}(m-1)\left\{\left[(1-k) \sigma_{1}^{m-2}+k h\left(\sigma_{1}-h \sigma_{2}\right)^{m-2}\right]\right. \\
& {\left[(1-k) \sigma_{2}^{m-2}+k h^{2}\left(\sigma_{1}-h \sigma_{2}\right)^{m-2}\right]} \\
& \left.-k h\left(\sigma_{1}-h \sigma_{2}\right)^{m-2} k h\left(\sigma_{1}-h \sigma_{2}\right)^{m-2}\right\} \dot{\sigma}_{1}
\end{aligned}
$$

Equation A2 is rearranged to

$$
\begin{aligned}
& \left\{\left[(1-k) \sigma_{2}^{m-2}+k h^{2}\left(\sigma_{1}-h \sigma_{2}\right)^{m-2}\right] \dot{\varepsilon}_{1}+k h\left(\sigma_{1}-h \sigma_{2}\right)^{m-2} \dot{\varepsilon}_{2}\right\} \sigma_{\mathrm{eq}}^{m} \\
& =\sigma_{\mathrm{eq}} \dot{\varepsilon}_{\mathrm{eq}}\left[1-w(m-1) \varepsilon_{\mathrm{eq}} / \sigma_{\mathrm{eq}}\right](1-k) \\
& {\left[(1-k) \sigma_{1}^{m-1} \sigma_{2}^{m-2}+k\left(\sigma_{1}-h \sigma_{2}\right)^{m-2}\left(h^{2} \sigma_{1}^{m-1}+\sigma_{1} \sigma_{2}^{m-2}\right)\right]} \\
& +\sigma_{\mathrm{eq}} \varepsilon_{\mathrm{eq}}(m-1)\left[(1-k)^{2} \sigma_{1}^{m-2} \sigma_{2}^{m-2}+k h(1-k)\right. \\
& \left(\sigma_{1}-h \sigma_{2}\right)^{m-2}\left(h \sigma_{1}^{m-2}+\sigma_{2}^{m-2}\right) \\
& \left.+k^{2} h^{2}(h-1)\left(\sigma_{1}-h \sigma_{2}\right)^{2 m-4}\right] \dot{\sigma}_{1}
\end{aligned}
$$

According to the strain energy principle

$\sigma_{\mathrm{eq}} \dot{\varepsilon}_{\mathrm{eq}}=\sigma_{1} \dot{\varepsilon}_{1}+\sigma_{2} \dot{\varepsilon}_{2}$

Substitution of Eq A4 into Eq A3 gives

$$
\begin{aligned}
& \left\{\left[(1-k) \sigma_{2}^{m-2}+k h^{2}\left(\sigma_{1}-h \sigma_{2}\right)^{m-2}\right] \dot{\varepsilon}+k h\left(\sigma_{1}-h \sigma_{2}\right)^{m-2} \dot{\varepsilon}\right\} \sigma_{\mathrm{eq}}^{m} \\
& =\left(\sigma_{1} \dot{\varepsilon}_{1}+\sigma_{2} \dot{\varepsilon}_{2}\right)\left[1-w(m-1) \varepsilon_{\mathrm{eq}} / \sigma_{\mathrm{eq}}\right](1-k) \\
& \quad\left[(1-k) \sigma_{1}^{m-1} \sigma_{2}^{m-2}+k\left(\sigma_{1}-h \sigma_{2}\right)^{m-2}\left(h^{2} \sigma_{1}^{m-1}+\sigma_{1} \sigma_{2}^{m-2}\right)\right] \\
& \quad+\sigma_{\mathrm{eq}} \varepsilon_{\mathrm{eq}}(m-1) \\
& \quad\left[(1-k)^{2} \sigma_{1}^{m-2} \sigma_{2}^{m-2}+k h(1-k)\left(\sigma_{1}-h \sigma_{2}\right)^{m-2}\left(h \sigma_{1}^{m-2}+\sigma_{2}^{m-2}\right)\right. \\
& \left.\quad+k^{2} h^{2}(h-1)\left(\sigma_{1}-h \sigma_{2}\right)^{2 m-4}\right] \dot{\sigma}_{1}
\end{aligned}
$$

Substitution of Eq 18-21 into Eq A5 gives

$$
\begin{aligned}
\sigma_{\mathrm{eq}}^{m} \sigma_{1}^{m-2}\left(B_{3} \dot{\varepsilon}_{1}+B_{4} \dot{\varepsilon}_{2}\right)= & B_{1} \sigma_{1}^{2 m-4}\left(\sigma_{1} \dot{\varepsilon}_{1}+\sigma_{2} \dot{\varepsilon}_{2}\right) \\
& {\left[1-w(m-1) \varepsilon_{\mathrm{eq}} / \sigma_{\mathrm{eq}}\right] } \\
& +B_{2} \sigma_{\mathrm{eq}} \varepsilon_{\mathrm{eq}} \sigma_{1}^{2 m-4} \dot{\sigma}_{1}
\end{aligned}
$$

Equation 17 results from rearrangement of $\mathrm{Eq} \mathrm{A6.}$

\section{References}

1. Federal Register. Part II. Environmental Protection Agency, Department of Transportation, National Highway Traffic Safety Administration, Washington, Work2010

2. G.I. Taylor, Plastic Strain in Metals, J. Inst. Met., 1938, 62, p 307-338

3. G. Ambrogio, L. Filice, and F. Gagliardi, Formability of Lightweight Alloys by Hot Incremental Sheet Forming, Mater. Des., 2012, 34, p 501-508 
4. J.T. Carter, P.E. Krajewski, and R. Verma, The Hot Blow Forming of AZ31 Mg Sheet: Formability Assessment and Application Development, JOM, 2008, 60, p 77-81

5. S. Ha, S.J. Kim, S. Hong, C.D. Yim, D.I. Kim, J. Suh, K.H. Oh, and H.N. Han, Improvement of Ductility in Magnesium Alloy Sheet Using Laser Scanning Treatment, Mater. Lett., 2010, 64, p 425-427

6. J.A. Yasi, L.G. Hector, Jr., and D.R. Trinkle, Prediction of Thermal Cross-Slip Stress in Magnesium Alloys from Direct First Principles Data, Acta Mater, 2011, 59, p 5652-5660

7. S.L. Couling, J.F. Pashak, and L. Sturkey, Unique Deformation and Aging Characteristics of Certain Magnesium Base Alloys, Trans. ASM, 1959, 51, p 94-107

8. R.K. Mishra, A.K. Gupta, P.R. Rao, A.K. Sachdev, A.M. Kumar, and A.A. Luo, Influence of Cerium on the Texture and Ductility of Magnesium Extrusions, Scr. Mater., 2008, 59, p 562-565

9. R.K. Mishra, A.K. Gupta, R. Sikand, A.K. Sachdev, and L. Jin, Formability Enhancements in Hot Extruded Magnesium Alloys, Magnesium Technology 2011, W.H. Sillekens, S.R. Agnew, N.R. Neelameggham, and S.N. Mathaudhu, Ed., Feb 27-Mar 3, 2011 (San Diego), TMS, 2011, p 363-366

10. L.L. Rokhlin, Magnesium Alloys Containing Rare Earth Metals, Taylor \& Francis, New York, 2003

11. J. Senn and S. Agnew, Texture Randomization of Magnesium Alloys Containing Rare Earth Elements, Magnesium Technology 2008, M.O. Pekguleryuz, N.R. Neelameggham, R.S. Beals, and E.A. Nyberg, Ed., Mar 9-13, 2008 (New Orleans), TMS, 2008, p 153-158

12. J. Bohlen, M.R. Nürnberg, J.W. Senn, D. Letzig, and S.R. Agnew, The Texture and Anisotropy of Magnesium-Zinc-Rare Earth Alloy Sheets, Acta Mater., 2007, 55, p 2101-2112

13. T. Al-Samman and X. Li, Sheet Texture Modification in MagnesiumBased Alloys by Selective Rare Earth Alloying, Mater. Sci. Eng. A, 2011, 528, p 3809-3822

14. S. Sandlöbes, S. Zaefferer, I. Schestakow, S. Yi, and R. GonzalezMartinez, On the Role of Non-basal Deformation Mechanisms for the Ductility of Mg and Mg-Y Alloys, Acta Mater., 2011, 59, p 429-439

15. J. Zhang, X. Zhang, W. Li, F. Pan, and Z. Guo, Partition of Er Among the Constituent Phases and the Yield Phenomenon in a Semicontinuously Cast Mg-Zn-Zr Alloy, Scr. Mater, 2010, 63, p 367-370

16. K. Hantzsche, J. Wendt, K.U. Kainer, J. Bohlen, and D. Letzig, Mg Sheet: The Effect of Process Parameters and Alloy Composition on Texture and Mechanical Properties, JOM, 2009, 61, p 38-42

17. S.P. Keeler, Determination of Forming Limits in Automotive Stampings, Sheet Met. Ind., 1965, 42, p 683-691

18. G.M. Goodwin, Application of strain analysis to sheet metal forming problems in press shop. Metall, Ital., 60, 1968, P 767-774

19. ASTM E2218, 2002, Standard test method for determining forming limit curves

20. S.P. Keeler. On the Origins of the FLD, Forming Limit Diagrams: Concepts, Methods and Applications, R.H. Wagoner, K.S. Chan, and S.P. Keeler, Ed., (Warrendale), TMS, 1989, p 3-8

21. W.F. Hosford and R.M. Caddell, Metal Forming: Mechanics and Metallurgy, 4th ed., Cambridge University Press, New York, 2011

22. J. Li, J.E. Carsley, T.B. Stoughton, L.G. Hector Jr., and S.J. Hu, Forming Limit Analysis for Two-Stage Forming of 5182-O Aluminum Sheet with Intermediate Annealing, Int. J. Plast., 2013, doi: 10.1016/j.ijplas.2012.10.004

23. Z. Marciniak, J.L. Duncan, and S.J. Hu, Mechanics of Sheet Metal Forming, Butterworth-Heinemann, Burlington, 2002

24. T.B. Stoughton, A General Forming Limit Criterion for Sheet Metal Forming, Int. J. Mech. Sci., 2000, 42, p 1-42

25. R. Hill, On Discontinuous Plastic States with Special Reference to Localized Necking in Thin Sheets, J. Mech. Phys. Solids, 1952, 1, p 19-30

26. Z. Marciniak and K. Kuczynski, Limit Strains in the Processes of Stretch Forming Sheet Metal, Int. J. Mech. Sci., 1967, 9, p 609-620

27. J. Cao, H. Yao, A. Karafillis, and M.C. Boyce, Prediction of Localized Thinning in Sheet Metal Using a General Anisotropic Yield Criterion, Int. J. Plast., 2000, 16, p 1105-1129

28. T.J. McCarron, K.E. Kain, G.T. Hahn, and W.F. Flanagan, Effect of Geometrical Defects in Forming Sheet Steel by Biaxial Stretching, Met. Mater. Trans. A, 1988, 19, p 2067-2074

29. A. Ghazanfari and A. Assempour, Calibration of Forming Limit Diagrams Using a Modified Marciniak-Kuczynski Model and an Empirical Law, Mater. Des., 2012, 34, p 185-191
30. J.Y. Min, J.P. Lin, J.Y. Li, and W.H. Bao, Investigation on Hot Forming Limits of High Strength Steel 22MnB5, Comput. Mater. Sci., 2010, 49, p 326-332

31. L. Zhang and J. Wang, Modeling the Localized Necking in Anisotropic Sheet Metals, Int. J. Plast., 2012, 39, p 103-118

32. S. Storen and J.R. Rice, Localized Necking in Thin Sheets, J. Mech. Phys. Solids, 1975, 23, p 421-441

33. X.H. Zhu, K. Weimann, and A. Chandra, A Unified Bifurcation Analysis of Sheet Metal Forming Limits, J. Eng. Mater. Technol., 2001, 123, p 329-333

34. C.L. Chow and M. Jie, Forming Limits of AL 6022 Sheets with Material Damage Consideration-Theory and Experimental Validation, Int. J. Mech. Sci., 2004, 46, p 99-122

35. W.F. Hosford, On Yield Loci of Anisotropic Cubic Metals, Proceedings of the 7th North American Metalworking Conference SME, May 13-16, 1979 (Dearborn), 1979, p 191-197

36. M. Jie, C.H. Cheng, L.C. Chan, and C.L. Chow, Forming Limit Diagrams of Strain-Rate-Dependent Sheet Metals, Int. J. Mech. Sci., 2009, 51, p 269-275

37. F. Barlat and J. Lian, Plastic Behavior and Stretchability of Sheet Metal. Part I: A Yield Function for Orthotropic Sheets Under Planar Stress Conditions, Int. J. Plast., 1989, 5, p 51-66

38. F. Barlat, D.J. Lege, and J.C. Brem, A Six Component Yield Function for Anisotropic Metals, Int. J. Plast., 1991, 7, p 693-712

39. F. Barlat, R.C. Becker, Y. Hayashida, Y. Maeda, M. Yanagawa, K. Chung, J.C. Brem, D.J. Lege, K. Matsui, S.J. Murtha, and S. Hattori, Yielding Description for Solution Strengthened Aluminum Alloys, Int. J. Plast., 1997, 13, p 385-401

40. F. Barlat, Y. Maeda, and K. Chung, Yield Function Development for Aluminum Alloys Sheets, J. Mech. Phys. Solids, 1997, 45, p $1727-$ 1763

41. F. Barlat, J.C. Brem, J.W. Yoon, K. Chung, R.E. Dick, D.J. Lege, F. Pourboghrat, S.H. Choi, and E. Chu, Plane Stress Yield Function for Aluminum Alloy Sheets-Part I: Theory, Int. J. Plast., 2003, 19, p 1297-1319

42. F. Barlat, H. Aretz, J.W. Yoon, M.E. Karabin, J.C. Brem, and R.E. Dick, Linear Transformation Based Anisotropic Yield Function, Int. J. Plast., 2005, 21, p 1009-1039

43. O. Cazacu, B. Plunkett, and F. Barlat, Orthotropic Yield Criterion for Hexagonal Closed Packed Metals, Int. J. Plast., 2006, 22, p 1171-1194

44. R. Hill, A Theory of the Yielding and Plastic Flow of Anisotropic Metals, Proc. R. Soc. Lond. Ser. A, 1948, 193, p 281-297

45. T. Naka, T. Uemori, R. Hino, M. Kohzu, K. Higashi, and F. Yoshida, Effects of Strain Rate, Temperature and Sheet Thickness on Yield Locus of AZ31 Magnesium Alloy Sheet, J. Mater. Process. Technol., 2008, 201, p 395-400

46. X.H. Zhu, S.A. Majlessi, E.C. Aifantis, Predicting the Forming Limit Diagram (FLD) for Sheet Metals with Planar Anisotropy, SAE Paper No. 1998-980080

47. F. Abu-Farha, R. Verma, and L.G. Hector, Jr., High Temperature Composite Forming Limit Diagrams of Four Magnesium AZ31B Sheets Obtained by Pneumatic Stretching, J. Mater. Process. Technol., 2012, 212, p 1414-1429

48. K. Siegert, S. Jäger, and M. Vulcan, Pneumatic Bulging of Magnesium AZ31 Sheet Metals at Elevated Temperatures, CIRP Annu. Manuf. Technol., 2003, 52, p 241-244

49. H.J. Kim, S.C. Choi, K.T. Lee, and H.Y. Kim, Experimental Determination of Forming Limit Diagram and Springback Characteristics of AZ31B Mg Alloy Sheets at Elevated Temperatures, Mater. Trans., 2008, 42, p 1112-1119

50. Y. Kim, C. Kim, S. Lee, S. Won, and S. Hwang, Forming Limits for Anisotropic Sheet Metal, JSME Int. J. Ser. A, 2003, 46, p 627-634

51. L. Zhang, Y.J. Yin, Y.Q. Chen, and M.D. Xue, Damage and Forming Limit Analysis in Porous Ductile Sheet Metals at Room or Elevated Temperatures, Mater. Sci. Technol., 2003, 19, p 1355-1360

52. P.M. Dixit and U.S. Dixit, Modeling of Metal Forming and Machining Processes, Springer, London, 2008

53. J.Y. Min, J.P. Lin, Y. Cao, W.H. Bao, and Z.G. Lu, Effect of Necking Types of Sheet Metal on the Left-Hand Side of Forming Limit Diagram, J. Mater. Process. Technol., 2010, 210, p 1070-1075

54. J.Y. Min, J.T. Carter, L.G. Hector Jr., R. Verma, and J.P. Lin, Localized Deformation Bands and Yield Point Elongation in Magnesium Alloy Sheet ZEK100-O, Proceedings of 9th International Conference on 
Magnesium Alloys and their Applications, W.J. Poole and K.U. Kainer, Ed., July 8-12, 2012 (Vancouver), TMS, 2012, p 461-466

55. M.R. Barnett, M.D. Nave, and A. Ghaderi, Yield Point Elongation Due to Twinning in a Magnesium Alloy, Acta Mater., 2012, 60, p 1433-1443

56. Y.J. Wu, R. Zhu, J.T. Wang, and W.Q. Ji, Role of Twinning and Slip in Cyclic Deformation of Extruded Mg-3\%Al-1\%Zn Alloys, Scr. Mater. 2010, 63, p 1077-1080

57. J.R. Davis, Aluminum and Aluminum Alloys, ASM International, 1993

58. J.E. Hatch, Aluminum: Properties and Physical Metallurgy, ASM International, 1984
59. C.C. Tasan, J.P.M. Hoefnagels, C.H.L.J. ten Horn, and M.G.D. Geers, Experimental Analysis of Strain Path Dependent Ductile Damage Mechanics and forming Limits, Mech. Mater, 2009, 41, p 1264-1276

60. S. Savic and L.G. Hector Jr., Tensile Deformation and Fracture of Press Hardened Boron Steel Using Digital Image Correlation, SAE Paper No. 2007-01-0790

61. S. Savic, L.G. Hector, Jr., and J. Fekete, A Digital Image Correlation Study of Plastic Deformation and Fracture in Fully Martensitic Steels, Exp. Mech., 2010, 50, p 99-110 